\section{Commentary: Don't stop operating! Surgery is still an important part of the definitive treatment approach to esophageal squamous cell carcinoma after neoadjuvant chemoradiation therapy}

\author{
Amit Katz, MD, and Moishe Liberman, MD, PhD
}

Neoadjuvant chemoradiotherapy (nCRT) has become the standard of care for patients with locally advanced esophageal squamous cell carcinoma (ESCC). It is reported that the pathological complete response rate after nCRT may be up to $49 \%{ }^{1}$. The relatively high rate of pathologic complete response combined with the fact that esophagectomy is perceived by many clinicians as a high-risk surgery with poor outcomes has led many to advocate for a wait and see approach with close follow-up, including positron emission computed tomography, endoscopic ultrasound, and frequent endoscopic bite-on-bite biopsy in the area of treated tumors.

Tang and colleagues ${ }^{2}$ from Fudan University, Shanghai, report on an in-depth analysis of the pathological response rates of 138 patients with ESCC who had residual tumors after nCRT. The authors found that residual tumor cells can exist in any layer of the esophagus, and their distribution among layers is equal. The majority of patients $(>80 \%)$ had residual tumors in the mucosa or submucosa; however, approximately half had rare residual tumor (ie, tumor regression grade 2), which signifies that they had very small amounts of cancer cells in these layers. In $16 \%$ of patients, a residual tumor was found only in

From the Division of Thoracic Surgery, Department of Surgery, CETOC-CHUM Endoscopic Tracheobronchial and Oesophageal Center, University of Montréal, Montréal, Québec, Canada.

Disclosures: The authors reported no conflicts of interest.

The Journal policy requires editors and reviewers to disclose conflicts of interest and to decline handling or reviewing manuscripts for which they may have a conflict of interest. The editors and reviewers of this article have no conflicts of interest.

Received for publication Oct 18, 2020; revisions received Oct 18, 2020; accepted for publication Oct 20, 2020; available ahead of print Oct 28, 2020.

Address for reprints: Moishe Liberman, MD, PhD, Division of Thoracic Surgery, CETOC, Centre Hospitalier de l'Université de Montréal Centre de Recherche du CHUM, Room R04.402-1, 900 Rue Saint-Denis, Montreal, Québec, H2X 0A9 Canada (E-mail: moishe.liberman@umontreal.ca).

J Thorac Cardiovasc Surg 2021;162:1642-3

$0022-5223 / \$ 36.00$

Copyright (c) 2020 by The American Association for Thoracic Surgery

https://doi.org/10.1016/j.jtcvs.2020.10.077

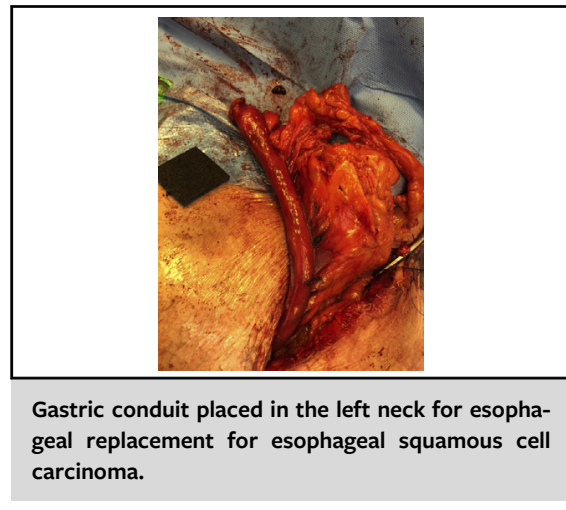

CENTRAL MESSAGE

Following neoadjuvant chemo-

radiotherapy in esophageal

squamous cell carcinoma, resid-

ual tumor cells may exist in any

layer of the esophagus. In many

cases, it is impossible to detect

residual cancer.

the muscularis propria, adventitia/surrounding stroma, or lymph nodes. In $60 \%$ of patients, the location of the residual cancer and the tumor regression grade made it difficult to identify residual cancer using current surveillance techniques. The study includes 78 patients who were deemed to be clinical complete responders, when in fact twothirds of these patients had nonpathological complete response. In this specific group of patients, the residual tumors of more than $40 \%$ of patients could not be diagnosed with bite-on-bite biopsy, and were barely identified by positron emission computed tomography and endoscopic ultrasound.

In the eyes of clinicians and patients, the decisionmaking process regarding treatment strategy is most challenging in situations where a patient demonstrates complete clinical response. This study and others ${ }^{3,4}$ have shown that clinical complete response does not predict a pathological complete response in more than $60 \%$ of patients after nCRT. The current study adds very important information regarding the tumor regression pattern of ESCC after nCRT, and the resulting difficulty in detecting residual tumor with the currently available surveillance techniques.

In our opinion, as long as there is no significant progress in the ability to accurately detect a pathological complete 
response using clinical investigation, the wait and see approach can result in missing the so-called curable window. Therefore, in patients with ESCC and acceptable surgical risk, we strongly recommend esophagectomy, even in a case of complete clinical response. We are impatiently awaiting the important results of the Neoadjuvant Chemoradiotherapy for Esophageal Squamous Cell Carcinoma versus Definitive Chemoradiotherapy with Salvage Surgery as Needed trial (ClinicalTrials.gov identifier: NCT04460352), which addresses this issue and we encourage centers from all over the world to actively participate.

\section{References}

1. Van Hagen P, Hulshof MC, van Lanschot JJ, Steyerberg EW, van Berge Henegouwen MI, Wijnhoven BP, et al. Preoperative chemoradiotherapy for esophageal or junctional cancer. $N$ Engl J Med. 2012;366:2074-84.

2. Tang H, Jiang D, Zhang S, Zeng Z, Tan L, Hou Y, et al; Zhongshan NCRT-EC working group. Residual tumor characteristics of esophageal squamous cell carcinoma after neoadjuvant chemoradiotherapy. J Thorac Cardiovasc Surg. 2021;162:1632-41.

3. Chao YK, Chuang WY, Yeh CJ, Chang HK, Tseng CK. Anatomical distribution of residual cancer in patients with oesophageal squamous cell carcinoma who achieved clinically complete response after neoadjuvant chemoradiotherapy. Eur J Cardiothorac Surg. 2018;53:201-8.

4. Cheedella NK, Suzuki A, Xiao L, Hofstetter WL, Maru DM, Taketa T, et al. Association between clinical complete response and pathological complete response after preoperative chemoradiation in patients with gastroesophageal cancer: analysis in a large cohort. Ann Oncol. 2013;24:1262-6.
See Article page 1632.

\section{Commentary: The Hydra: Residual esophageal squamous cell tumor after neoadjuvant chemoradiotherapy}

\author{
Jules Lin, MD
}

In this issue of the Journal, Tang and colleagues ${ }^{1}$ describe characteristics of residual esophageal squamous cell carcinoma (ESCC) after neoadjuvant chemoradiotherapy (nCRT) at the time of esophagectomy. They conclude that residual tumors may be difficult to identify on endoscopic biopsy because of the small amount of viable tumor cells in the superficial layers. The results are of interest especially as debate continues on whether patients with ESCC with a complete clinical response after nCRT can be managed with surveillance.

The pathologic complete response in the CROSS (49\%) and NEOCRTEC5010 studies (43.2\%) was higher than the $26.2 \%$ rate in the current study. ${ }^{2,3}$ One possible explanation is that only patients with more advanced T3-4a disease were

\footnotetext{
From the Section of Thoracic Surgery, Department of Surgery, University of Michigan Medical Center, Ann Arbor, Mich.

Disclosures: The author reported no conflicts of interest.

The Journal policy requires editors and reviewers to disclose conflicts of interest and to decline handling or reviewing manuscripts for which they may have a conflict of interest. The editors and reviewers of this article have no conflicts of interest.

Received for publication Oct 11, 2020; revisions received Oct 11, 2020; accepted for publication Oct 14, 2020; available ahead of print Oct 17, 2020.

Address for reprints: Jules Lin, MD, Section of Thoracic Surgery, 1500 E Medical Center Drive, 2120TC/5344, Ann Arbor, MI 48109-5344 (E-mail: juleslin@ umich.edu).

J Thorac Cardiovasc Surg 2021;162:1643-4

$0022-5223 / \$ 36.00$

Copyright (C) 2020 by The American Association for Thoracic Surgery

https://doi.org/10.1016/j.jtcvs.2020.10.044
}

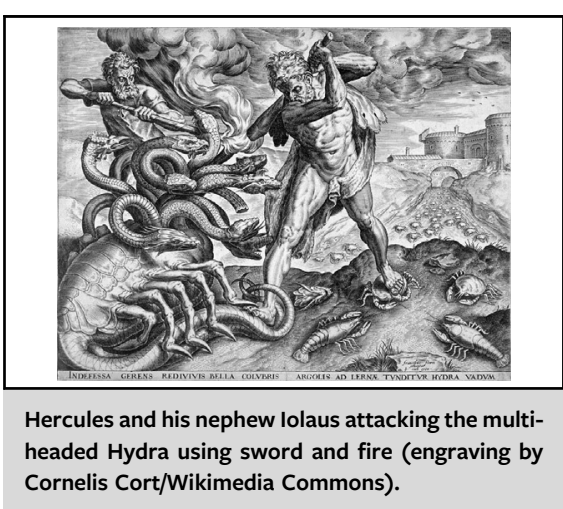

CENTRAL MESSAGE

Results of this study suggest that residual ESCC may be difficult to detect after neoadjuvant therapy because of only small amounts of viable tumor in the superficial layers.

included in the current study. Is it possible that patients with more superficial disease are more likely to have a complete response and less likely to have hidden disease deeper in the esophageal wall? In addition, there were substantial differences between the clinical $\mathrm{T}$ stage and the pretreatment prepT stage, the original tumor depth based on pathologic evidence of tumor regression. It is unclear if this is due to inadequate clinical staging, because many patients did not undergo endoscopic ultrasound, or difficulty determining the prepT stage due to treatment-related changes. 